\title{
Morbidade Febril Puerperal em Pacientes Infectadas pelo HIV
}

\author{
Puerperal Morbidity in HIV-positive Women
}

Andrea De Marcos, Luciana Lunardi, Prescilla Chow Lindsey Abes Mahmed Amed, Adauto Castelo Filho

\begin{abstract}
RESUMO
Objetivo: avaliar as taxas de morbidade febril puerperal em pacientes infectadas pelo HIV e sua correlação com a via de parto, duração do trabalho de parto, tempo de rotura de membranas, número de células $\mathrm{CD}^{+}$e carga viral do HIV periparto.

Métodos: foram incluidas 207 gestantes infectadas pelo HIV, com seguimento pré-natal e parto entre maio de 1997 e dezembro de 2001, sendo 32 submetidas a parto vaginal e 175 a cesárea. Do total de pacientes, 62,8\% foram submetidas a cesárea eletiva. A idade média no grupo analisado foi de 27,4 anos, 25,6\% eram nuliparas e 26\% primiparas, com idade gestacional média de 37,8 semanas no momento do parto. A contagem média de células $C D 4^{+}$foi de 481 células $/ \mathrm{mm}^{3}$ e da carga viral do HIV de 49.100 cópias/ $\mathrm{mL}$, ambas no final da gestação.

Resultados: a morbidade febril puerperal ocorreu em 34 pacientes, sendo 33 pós-cesárea e 1 pós-parto vaginal. O tipo mais comum de intercorrência infecciosa pós-cesárea foi infecção de cicatriz cirúrgica (13\% dos casos de infecção). Os fatores analisados, como duração do trabalho de parto, tempo de rotura de membranas, contagem de células $C D 4^{+}$ou carga viral do HIV periparto, não interferiram na taxa de morbidade febril puerperal.

Conclusões: A incidência de morbidade febril puerperal foi de 16,8\%, sendo mais freqüente pós-cesárea $(18,9 \%)$ que pós-parto vaginal $(3,1 \%)$. Os demais fatores não mostraram relação significativa com a taxa de morbidade febril puerperal.
\end{abstract}

PALAVRAS-CHAVES: AIDS. Infecção puerperal. Transmissão vertical. Cesárea. Parto normal.

\section{Introdução}

Nascem por ano, no mundo, mais de 500.000 crianças contaminadas pelo vírus da imunodeficiência humana (HIV). Em 1994, 69\% dos casos notificados, no Brasil, eram homo/ bissexuais, mas devido à "feminização" da epidemia, a razão de sexo é de dois homens para uma mulher infectada desde 1997. Cerca de $85 \%$ das mulheres infectadas estão em idade reprodutiva, ocorrendo a transmissão materno-fetal (TMF) do HIV.

Núcleo de Patologias Infecciosas na Gravidez (NUPAIG) Escola Paulista de Medicina

Andrea De Marcos

Rua Princesa Isabel, 64 - apto 114 - Brooklin

04601-000 - São Paulo - SP

Fone: (11) 5042-2877

e-mail: andreademarcos@ig.com.br
Diversos fatores influem na taxa de TMF, como tempo de evolução da infecção, estado de portador ou doença, quantidade de vírus no organismo materno (carga viral), presença de doenças sexualmente transmissiveis e de corioamnionite, procedimentos invasivos durante a gestação ou parto, idade gestacional no momento do parto, duração do trabalho de parto e da rotura das membranas e presença de aleitamento materno.

$\mathrm{Na}$ tentativa de reduzir a TMF, pode-se utilizar, durante a gestação e o parto, drogas antiretrovirais. O primeiro estudo foi realizado por Connor et al. ${ }^{1}$, em 1994, para redução da TMF, denominado "Aids Clinical Trial Group" (ACTG) 076, e mostrou redução de $67,5 \%$ na taxa de TMF, no grupo que fez uso da zidovudina (AZT). Vários outros esquemas medicamentosos vem sendo estudados na tentativa de redução da TMF como, por exemplo, a nevirapina. Atualmente dá-se prefe- 
rência para a utilização de associações de drogas anti-retrovirais no intuito de tornar a carga viral do HIV indetectável no momento do parto.

O papel da via de parto na TMF foi extensamente analisado vários trabalhos sendo que a cesárea vem sendo relacionada com as menores taxas de TMF. Frenkel ${ }^{2}$, na $6^{\text {a }}$ Conferência sobre Retroviroses e Infecções Oportunistas, em Chicago, 1999, questionou se a cesárea apresentava beneficio na redução da TMF nas pacientes em uso de terapia combinada com antivirais e carga viral do HIV indetectável, pois já havia sido relatada TMF zero em 48 gestantes com carga viral indetectável (<500 cópias / $\mathrm{mL}$ ).

A cesárea, principalmente aquela realizada durante o trabalho de parto ou após rotura de membranas, sempre esteve relacionada a aumento de morbidade puerperal. A infecção é a principal causa de morbidade pós-parto, sendo a endometrite, infecção urinária e infecção de ferida cirúrgica os locais mais freqüentes ${ }^{3}$. Quando se compara a cesárea a partos não cirúrgicos, observa-se que a primeira está associada a aumento da morbidade materna e, dentre as cesáreas, a realizada de forma eletiva apresenta menos complicações infecciosas que aquelas realizadas de urgência ${ }^{4}$. É esperado que mulheres infectadas pelo HIV com imunodeficiência apresentem maior risco de complicações infecciosas pós-cesárea, principalmente quando esta não é realizada de forma eletiva.

Vários estudos têm sido realizados no intuito de avaliar os riscos de infecção pós-parto em pacientes infectadas pelo HIV. Semprini et al. ${ }^{5}$ avaliaram as taxas de complicações pós-cesárea em puérperas infectadas ou não pelo HIV, todas com uso de antibiótico. As complicações maiores incluíram a necessidade de hemotransfusão, presença de pneumonia ou derrame pleural, peritonite, septicemia, coagulação intravascular disseminada ou tromboembolismo. As complicações menores incluíram febre superior a $38^{\circ} \mathrm{C}$, excluídas as primeiras 24 horas pós-parto, infecção de ferida cirúrgica, endometrite ou infecção urinária. Foram observadas seis complicações maiores no grupo infectado pelo HIV e apenas um caso no grupo não infectado. Ocorreram 42 complicações menores no grupo infectado pelo HIV e 10 no grupo não infectado. O aumento na incidência de complicações menores foi significativo nas pacientes infectadas pelo HIV submetidas a cesárea, principalmente naquelas imunodeprimidas.

Watts et al. ${ }^{6}$ analisaram 497 mães com contagem de células $\mathrm{CD}^{+}{ }^{+}$inferior a 500 células por $\mathrm{mm}^{3}$. Foram avaliadas a incidência de morbidade febril puerperal, com os seguintes resultados: $26 \%$ na cesárea eletiva, $40 \%$ na cesárea não eletiva, $19 \%$ no parto vaginal instrumental e $12 \%$ no par- to vaginal espontâneo. As infecções periparto ocorreram em 19,5\% e 16\%, respectivamente naquelas com células $\mathrm{CD}^{+}{ }^{+}$infeirores a 200 células $/ \mathrm{mm}^{3}$ e superiores a 200 células $/ \mathrm{mm}^{3}$, diferença não significativa.

Grubert et al. ${ }^{7}$ e Vimercati et al. ${ }^{8}$ realizaram estudos com mulheres infectadas pelo HIV comparadas ao grupo controle não infectado e que foram submetidas a cesárea eletiva com uso de antibioticoterapia. Ambos os trabalhos mostraram aumento nas taxas de complicações maiores e menores no grupo infectado quando comparado ao não infectado pelo HIV.

Rodriguez et al. ${ }^{9}$, analisaram 86 pacientes infectadas pelo HIV e 86 controles. A taxa de complicações menores foi maior no grupo infectado pelo HIV (66,3 e 41,8\%, respectivamente), sendo a morbidade febril a mais comum. As pacientes com carga viral do HIV entre 1.001 e 10.000 cópias/ $\mathrm{mm}^{3}$ tiveram taxa maior de complicações (8 vezes maior) quando comparadas àquelas com carga viral do HIV indectectável.

Considerando as evidências mostradas nesses trabalhos de que a cesárea realizada em mulheres infectadas pelo HIV está associada a maiores taxas de infecção ou morbidade pós-operatória naquelas com contagem de células $\mathrm{CD}^{+}$ inferior a 200 células $/ \mathrm{mm}^{3}$ ou carga viral do HIV detectável periparto, o presente estudo visa avaliar a incidência dessas intercorrências infecciosas relacionando essas taxas com a via de parto, fatores imunológicos e virológicos maternos.

\section{Pacientes e Métodos}

Trata-se de estudo de coorte retrospectivo, no qual gestantes infectadas pelo HIV foram avaliadas quanto à presença de intercorrência infecciosa puerperal. Esse projeto de estudo foi avaliado e aprovado pelo Comitê de Ética Médica da Escola Paulista de Medicina/UNIFESP.

Foram incluídas nesse estudo as pacientes que preencheram todos os seguintes critérios: ser infectada pelo HIV, com sorologia para HIV confirmatória nesse serviço; ter sido atendida em pré-natal, entre maio de 1997 e dezembro de 2001 no Núcleo de Patologias Infecciosas na Gravidez (NUPAIG), Escola Paulista de Medicina (EPM) Universidade Federal de São Paulo (UNIFESP), ter iniciado o pré-natal até a $32^{\mathrm{a}}$ semana de gestação e ter pelo menos duas consultas de pré-natal até o parto; ter seu parto realizado no Hospital São Paulo, de acordo com as condutas desse serviço, até a data limite de 31 de dezembro de 2001 . 
O presente estudo incluiu, inicialmente, 327 gestantes infectadas pelo HIV, no momento da primeira consulta de pré-natal no NUPAIG, com data de entrada entre maio de 1997 e dezembro de 2001. Desse total de pacientes, 120 foram excluídas por não apresentarem algum dos critérios de elegibilidade descritos acima, distribuídos da seguinte maneira: 58 não tiveram seus partos realizados no Hospital São Paulo, 23 não tiveram seus partos até a data limite de inclusão de 31 de dezembro de 2001, 16 evoluíram para abortamento, 11 compareceram a apenas uma consulta de pré-natal, 6 abandonaram os cuidados de pré-natal nesse serviço e 6 diagnósticos de soropositividade para HIV não foram confirmados no NUPAIG.

A média de idade nas 207 mulheres estudadas foi de 27,4 anos. Quanto à paridade, 53 eram nulíparas $(25,6 \%)$ e 54 primíparas $(26,0 \%)$. As outras 100 pacientes tinham de 2 até 7 partos anteriores e corresponderam a $48,3 \%$ da população analisada. A idade gestacional média, no momento do parto, foi de 37,8 semanas.

A assistência pré-natal no NUPAIG é realizada por equipe multiprofissional, constituída por médicos (obstetras e infectologistas), psicólogos, enfermeira obstétrica e assistente social. São realizados os exames de rotina de pré-natal, sorologias (sífilis, toxoplasmose, rubéola, citomegalia, doença de Chagas e hepatites A, B e C), além da contagem de células $\mathrm{CD}^{+}$e da determinação da carga viral do HIV. As sorologias inicialmente negativas, a contagem de células $\mathrm{CD}^{+}$e a determinação da carga viral do HIV, são repetidas trimestralmente. Sempre que houver mudança no esquema de drogas anti-retrovirais ou abandono dos medicamentos pela gestante, são feitas as orientações adequadas e repetição dos exames um mês após essa data. É realizada ultra-sonografia para confirmação da idade gestacional e estudo morfológico, no setor de Medicina Fetal, da EPM/UNIFESP por volta da $20^{a}$ semana de gestação.

A eficácia do esquema anti-retroviral utilizado ou a necessidade de sua introdução, caso a paciente esteja sem tratamento, é avaliada com os resultados dos exames iniciais. As pacientes que não têm indicação de uso de anti-retroviral para tratamento próprio fazem uso profilático de AZT para prevenção da TMF, segundo a recomendação do ACTG 076. Para aquelas com indicação materna do uso de drogas, o esquema anti-retroviral deve seguir as normas recomendadas para o tratamento de adultos do Ministério da Saúde, 2000, Brasil, utilizando-se esquema duplo ou triplo de drogas incluíndo, sempre que possível, o AZT.
Durante a internação para resolução obstétrica é completado o ACTG 076 com infusão de AZT endovenoso até o nascimento do concepto. Realiza-se antibioticoterapia profilática, após o clampeamento do cordão umbilical, de acordo com os protocolos do Hospital São Paulo. Após o parto, é feita inibição da lactação.

No dia da alta hospitalar, as pacientes são orientadas a procurar o serviço de pré-natal se apresentarem qualquer uma das seguintes alterações: febre, dor na incisão cirúrgica ou drenagem de secreção purulenta pela mesma, loquiação fétida ou sinais inflamatórios nas mamas. Na retirada de pontos a paciente foi submetida a exame ginecológico visando, principalmente, a avaliação das mamas, para pesquisa de mastite, e da ferida cirúrgica, observando-se a presença ou não de secreções ou sinais inflamatórios. Na presença de sintomas urinários foi solicitada urocultura para pesquisa de infecção urinária pós-parto. A consulta pós-parto foi realizada por volta do $40^{\circ}$ dia pós-operatório, com novo exame clínico e ginecológico completo.

Foram utilizados os critérios e conceitos de infecção hospitalar estabelecidos pelo NNISS "National Nosocomial Infections Surveillance System", pertencente ao CDC em associação com hospitais americanos, criado inicialmente em 1970 e atualizado anualmente ${ }^{10}$. Foram consideradas como morbidade febril puerperal as infecções pós-parto que ocorreram em órgãos genitais, pulmão, mamas ou vias urinárias. Os dados pesquisados foram divididos em referentes ao parto e ao puerpério.

Para analisar a associação entre variáveis no parto e no puerpério com a incidência de intercorrências infecciosas puerperais, em mulheres infectadas pelo HIV, foram utilizados testes não paramétricos $\left(\chi^{2}\right.$ e teste exato de Fisher).

A probabilidade de intercorrência infecciosa puerperal foi estimada por métodos utilizando regressão logística múltipla. O nível de significância foi estabelecido em $5 \%$.

\section{Resultados}

Das 207 pacientes analisadas, o parto vaginal foi realizado em $32(15,4 \%$ dos casos) e a cesárea nas 175 restantes, sendo que 130 foram submetidas a cesárea eletiva (62,8\% dos casos) e 45 a cesárea não eletiva $(21,7 \%)$, incluindo-se nesse grupo as cesáreas de urgência ou realizadas na vigência de rotura de membranas ou de trabalho de parto ${ }^{1}$. 


\section{Morbidade febril puerperal}

Durante o período de estudo, foram encontrados 35 registros de morbidade febril puerperal em 34 pacientes, sendo 2 focos em uma mesma paciente (pulmonar e cicatriz cirúrgica). A taxa geral de morbidade febril puerperal foi de $16,9 \%$. Desse total de infecções, 9 casos foram diagnosticados durante o período de internação $(25,7 \%)$ e os 26 restantes $(74,3 \%)$ por procura direta da paciente na presença de sinais inflamatórios ou infecciosos, no momento da retirada de pontos, ou na consulta pós-parto, todas realizadas no NUPAIG.

\section{Análise de dados referentes ao parto}

Do total de 207 pacientes analisadas, apenas duas apresentavam infecção no momento da internação $(0,9 \%)$, sendo um caso de condiloma acuminado genital com infecção secundária e outro de corioamnionite. Essas duas pacientes foram submetidas a cesárea não eletiva, com antibioticoterapia profilática, e não apresentaram morbidade febril puerperal.

A contagem de células $\mathrm{CD}^{+}$no final da gestação, dado presente em 184 prontuários, teve um valor médio de 481,1 células $/ \mathrm{mm}^{3}$. Nas pacientes com morbidade febril puerperal, a média da contagem de células foi de 418,0 células $/ \mathrm{mm}^{3}$ e no grupo sem infecção foi de 493,9 células $/ \mathrm{mm}^{3}$. A taxa de infecção no grupo com contagem de células $\mathrm{CD}^{+}<200$ células $/ \mathrm{mm}^{3}$ foi de $22,2 \%$ e no grupo com contagem de células $\mathrm{CD}^{+}>200$ células / $\mathrm{mm}^{3}, 15,9 \%$. Não houve diferença significativa nas taxas de infecção nos grupos com contagem de células $\mathrm{CD}^{+}$maior ou menor que 200 células/ $\mathrm{mm}^{3}\left(\chi^{2}=0,652 ; \mathrm{p}=0,419\right)$.

A contagem de carga viral do HIV teve valor médio de 49.100 cópias/mL. Quando analisados os 34 casos que apresentaram infecção, observouse que o valor médio de carga viral do HIV nesse grupo foi de 33.820 cópias / mL. A taxa de infecção no grupo com carga viral do HIV menor que 1.000 cópias / $\mathrm{ml}$ foi de $17,4 \%$; entre 1.001 e 30.000 cópias / $\mathrm{mL}$ foi de $20,2 \%$ e acima de 30.000 cópias / $\mathrm{mL}$ foi de $12,3 \%$. Não houve diferença significativa nas taxas de infecção nos 3 grupos $\left(\chi^{2}=1,542 ; p=0,462\right)$. Dos 34 casos de infecção, 8 foram pacientes com carga viral abaixo de 1.000 cópias / $\mathrm{mL}(23,5 \%), 18$ pacientes com carga viral entre 1.001 e 30.000 cópias / $\mathrm{mL}(52,9 \%)$ e 7 pacientes com carga viral acima de 30.000 cópias / $\mathrm{mL}(20,5 \%)$.

No grupo submetido ao parto vaginal, houve apenas um caso de infecção $(3,1 \%)$ e no grupo submetido a cesárea, a taxa geral de infecção foi de $18,9 \%$, no total de 175 casos. Quando comparada a taxa de morbidade febril puerperal nas pacientes submetidas a cesárea (eletiva e não eletiva) e ao parto vaginal, observou-se um aumento significativo da taxa de infecção nos casos de cesárea $\left(\chi^{2}=4,878 ; p=0,027\right)$ (Tabela 1). Quando comparada à taxa de infecção nos dois grupos de cesárea (eletivas e não eletivas), observou-se que naquelas pacientes submetidas à cesárea eletiva a taxa foi de $19,2 \%$ (25 casos) e a cesárea não eletiva foi de $17,8 \%$ (8 casos), diferença não significativa (teste exato de Fisher $=1,0)($ Tabela 2$)$.

Tabela 1 - Incidência de infecções puerperais segundo o tipo de parto (vaginal e cesárea).

\begin{tabular}{lrcrrr}
\hline & \multicolumn{3}{c}{ Infecção } & \multicolumn{1}{c}{ Total } \\
& \multicolumn{2}{c}{ Sem } & \multicolumn{2}{c}{ Com } & n \\
& $\mathbf{n}$ & $\%$ & \multicolumn{1}{c}{$\mathbf{n}$} & $\%$ & \\
\hline Parto vaginal & 31 & 96,9 & 1 & 3,1 & 32 \\
Cesárea & 142 & 82,1 & 33 & 18,9 & 175 \\
Total & 173 & 83,6 & 34 & 16,4 & 207 \\
\hline
\end{tabular}

$\mathrm{n}=$ número; $\chi^{2}=4,878$

Tabela 2 - Incidência de infecções puerperais segundo o tipo de cesárea.

\begin{tabular}{lrrrrr}
\hline & \multicolumn{3}{c}{ Infecção } & & Total \\
& \multicolumn{2}{c}{ Sem } & \multicolumn{2}{c}{ Com } & n \\
& $\mathbf{n}$ & $\%$ & $\mathbf{n}$ & $\%$ & \\
\hline Cesárea eletiva & 105 & 80,8 & 25 & 19,2 & 130 \\
Cesárea não eletiva & 37 & 82,2 & 8 & 17,8 & 45 \\
Total & 142 & 81,1 & 33 & 18,8 & 175 \\
\hline
\end{tabular}

$\mathrm{n}=$ número; $\chi^{2}=0,046 ;$ Fisher $=1,0$

Das 207 pacientes estudadas, 149 foram submetidas a cesárea eletiva $(71,9 \%), 52$ tiveram período de trabalho de parto menor que 8 horas $(25,1 \%)$ e apenas 6 tiveram trabalho de parto maior que 8 horas $(2,9 \%)$. Em relação ao grupo que apresentou infecção, não houve nenhum caso de trabalho de parto com duração maior que 8 horas. Dos 34 casos de infecção, 3 ocorreram em intervalo inferior a 8 horas e os demais 31 foram em pacientes não submetidas a trabalho de parto. Não houve diferença significativa entre as taxas de infecção nos grupos submetidos ou não a trabalho de parto (teste exato de Fisher $=1,0$ ).

No grupo estudado, 153 pacientes não apresentaram rotura de membranas $(73,9 \%)$. Dos 54 casos de rotura de membranas, 35 apresentaram intervalo menor que 6 horas $(64,8 \%)$ e 19 intervalo maior que 6 horas $(35,1 \%)$. No grupo que apresentou infecção, 28 pacientes não apresentaram rotura de membranas $(82,3 \%)$. Das 6 restantes, 5 apresentaram rotura de membranas com intervalo menor que 6 horas $(14,7 \%)$ e somente uma teve intervalo maior que 6 horas $(2,9 \%)$. Não hou- 
ve diferença significativa nas taxas de infecção nos grupos com ou sem rotura de membranas $\left(\chi^{2}=2,233 ; p=0,327\right)$. Das 153 pacientes que não apresentaram rotura de membranas, 28 evoluiram com infecção $(18,3 \%)$. No grupo com rotura de membranas com intervalo menor que 6 horas, houve 5 casos de infecção do total de 35 casos $(14,3 \%)$, e no grupo com intervalo maior que 6 horas, 1 caso no total de 19 casos $(5,3 \%)$.

Das 207 pacientes analisadas, a duração do ato operatório foi obtida em 205 prontuários. Desse total, 184 pacientes $(89,7 \%)$ tiveram tempo cirúrgico menor que 2 horas. Das 21 pacientes com duração do ato operatório maior que 2 horas, 5 apresentaram infecção $(23,8 \%)$. Comparado com o grupo com duração menor que 2 horas, 29 (15,8\%) apresentaram infecção. Não houve diferença significativa nas taxas de infecção nos grupos com duração do ato cirúrgico maior ou menor que 2 horas $\left(\chi^{2}=0,883 ; p=0,347\right)$.

Das 207 pacientes estudadas, 2 apresentaram corioamnionite $(0,96 \%)$. Na análise das 34 pacientes com infecção, apenas 1 apresentou corioamnionite $(2,94 \%)$. Não houve diferença significativa nas taxas de morbidade febril puerperal nos 2 grupos $\left(\chi^{2}=1,658 ; p=0,198\right)$.

Do grupo de 207 pacientes infectadas pelo HIV , 185 receberam antibioticoterapia profilática (AtP) no momento do parto, correspondendo a 89,4\% do total de pacientes. Do grupo que apresentou infecção, 5 não receberam AtP (14,7\%). No grupo sem uso de AtP, 5 apresentaram infecção do total de 22 casos $(22,7 \%)$, ao passo que no grupo que fez uso de AtP, ocorreram 29 casos de infecção (15,7\%). Não houve diferença significativa nas taxas de infecção com uso profilático ou não de antibioticoterapia $\left(\chi^{2}=0,712 ; p=0,399\right)$.

\section{Análise de dados referentes ao puerpério}

Incluem-se em complicações maiores os seguintes sinais/sintomas: internação hospitalar prolongada, necessidade de hemotransfusão, presença de pneumonia ou derrame pleural, peritonite, septicemia, coagulação intravascular disseminada e tromboembolismo. Nesse estudo, ocorreu 1 caso de pneumonia $(0,48 \%), 2$ de trombose venosa profunda $(0,96 \%)$ e 4 de hemotransfusão $(1,93 \%)$, com um total de 7 casos de complicações maiores com taxa de 3,38\%, sendo apenas o caso de hemotransfusão pós-parto normal (Tabela 3).

Incluem-se em complicações menores os seguintes sinais / sintomas: presença de febre, de endometrite, infecção de ferida cirúrgica, mastite e infecção urinária. Nas 207 pacientes analisadas ocorreram 27 casos de infecção da ferida cirúrgica $(13 \%), 5$ casos de mastite $(2,4 \%)$ e 1 caso de endometrite $(0,48 \%)$, com um total de 33 casos de complicações menores $(15,9 \%)$, sendo todos póscesárea. Houve apenas 1 caso de morbidade febril pós-parto vaginal (Tabela 4).

Tabela 3 - Incidência de complicações maiores.

\begin{tabular}{lccccc}
\hline & \multicolumn{2}{c}{ Complicações maiores } & Total \\
& \multicolumn{2}{c}{ Sem } & \multicolumn{2}{c}{ Com } & n \\
& $\mathbf{n}$ & $\%$ & $\mathbf{n}$ & $\%$ & \\
\hline Pneumonia & 205 & 99,5 & 1 & 0,48 & 206 \\
Tromboembolismo & 205 & 99,0 & 2 & 0,96 & 207 \\
Hemotransfusão & 203 & 98,0 & 4 & 1,93 & 207 \\
Total complicações maiores & & & 7 & 3,38 & 207 \\
\hline
\end{tabular}

$\mathrm{n}=$ número

Tabela 4 - Incidência de complicações menores

\begin{tabular}{lccccc}
\hline & \multicolumn{3}{c}{ Complicações menores } & Total \\
& \multicolumn{2}{c}{ Sem } & \multicolumn{2}{c}{ Com } & n \\
& $\mathbf{n}$ & $\%$ & n & \multicolumn{1}{c}{$\%$} & \\
\hline Infecção da incisão cirúrgica & 180 & 86,9 & 27 & 13,0 & 207 \\
Mastite & 202 & 97,5 & 5 & 2,4 & 207 \\
Endometrite & 203 & 99,5 & 1 & 0,48 & 207 \\
Morbidade febril & 206 & 99,5 & 1 & 0,48 & 207 \\
Total complicações maiores & & & 34 & 16,4 & 207 \\
\hline
\end{tabular}

$\mathrm{n}=$ número

\section{Discussão}

Embora 33 dos 34 casos de infecção tenham ocorrido após cesárea, vale ressaltar que o grupo das pacientes submetidas a cesárea constituiu nossa maior casuística, com 175 casos. A diferença da taxa de infecção entre o parto vaginal $(3,1 \%)$ e a cesárea $(18,9 \%)$ foi estatisticamente significativa.

Dos 33 casos de infecção pós-cesárea entre as pacientes incluídas, 25 foram após cesáreas eletivas e oito casos em pacientes com cesárea não eletiva. Apesar de a maior parte dos casos ser de pacientes submetidas a cesárea eletiva, era esperado que o grupo com cesárea não eletiva apresentasse maior taxa de morbidade febril puerperal, como mostram os trabalhos anteriormente citados, o que não foi observado. Isto talvez possa ser explicado pelo predomínio de pacientes submetidas a cesárea eletiva e ao pequeno grupo no qual foi realizada cesárea não eletiva.

A cesárea sempre esteve relacionada com maiores taxas de morbidade febril puerperal, quando comparada ao parto vaginal. Deve-se lembrar, porém, que a cesárea eletiva apresenta maior risco de sangramento e prolongamento de incisão uterina comparada àquela realizada na vigência de trabalho de parto, devido ao segmento inferior 
não estar totalmente formado. Esse aumento de sangramento também pode explicar o aumento na taxa de morbidade febril puerperal nas pacientes submetidas a cesárea eletiva.

Quando analisamos a duração do ato operatório, vale ressaltar que o presente estudo foi realizado em um hospital-escola e os procedimentos, nele realizados, são executados por residentes. Mesmo assim podemos observar que $89,7 \%$ das pacientes incluidas no estudo tiveram tempo cirúrgico inferior a duas horas.

Não podemos analisar a influência da duração do trabalho de parto na taxa de morbidade febril puerperal, quando se analisa a duração do trabalho de parto em horas já que a maioria da população estudada teve sua resolução obstétrica por cesárea eletiva.

Quando avaliado o tempo decorrido entre a rotura das membranas e o nascimento do concepto, observamos que em 28 casos com infecção $(82,3 \%)$ esta ocorreu em pacientes submetidas a cesárea com bolsa íntegra, demonstrando que a rotura de membranas não foi fator de risco para a infecção em nosso grupo.

A contagem média de células $\mathrm{CD}^{+}$foi de 418,0 células $/ \mathrm{mm}^{3}$ no grupo com infecção e 493,90 células $/ \mathrm{mm}^{3}$ no grupo sem infecção. Trabalhos como o de Hanna et al. ${ }^{11}$, em 1997, mostraram não haver diferença na taxa de infecção pós-parto quando avaliadas as pacientes com contagem de células $\mathrm{CD}^{+}<200$ células $/ \mathrm{mm}^{3}$ ou $<500$ células $/ \mathrm{mm}^{3}$. Watts et al. ${ }^{6}$, em 2000, também encontraram taxas semelhantes de infecção quando analisadas pacientes com contagem de células CD4+ <200 (19,5\% infecção) e >200 células $/ \mathrm{mm}^{3}$ (16\% de infecção).

No presente estudo, $82,3 \%$ dos casos de infecção ocorreram no grupo com contagem de células $\mathrm{CD}^{+}>200$ células $/ \mathrm{mm}^{3}$, embora esse grupo represente a nossa maior amostragem $(75,8 \%$ dos pacientes analisados). Como apenas $24,2 \%$ da população estudada encontrava-se com contagem de células $\mathrm{CD}^{+}<200$ células $/ \mathrm{mm}^{3}$ enfatiza-se a importância da realização de adequado pré-natal, com seguimento conjunto com infectologista no intuito de melhorar as condições clínicas da paciente e, com isso, reduzir o risco de complicações infecciosas, tanto durante o pré-natal como no pós-parto. Embora fosse de se esperar que as pacientes com imunodepressão apresentassem maiores taxas de infecção, esse dado não foi confirmado no presente estudo, talvez pelo fato de que apenas $24,2 \%$ da população avaliada teve contagem de células $\mathrm{CD}^{+}<200$ células $/ \mathrm{mm}^{3}$.

Em relação à antibioticoterapia, a mesma foi utilizada em $89,4 \%$ das pacientes analisadas.
A prescrição do antibiótico não foi feita de modo homogêneo em todas as pacientes devido ao estudo ser retrospectivo, com duração de quase 5 anos. Não houve diferença significativa na taxa de morbidade febril puerperal no grupo com ou sem antibioticoterapia, mostrando que o seu uso não conferiu proteção. Mais uma vez talvez esses dados possam ser explicados pelo fato de que a maioria das cesáreas foi realizada eletivamente e em pacientes imunocompetentes.

No presente estudo, a maior parte dos casos de infecção foi de cicatriz cirúrgica, com um total de 27 casos, seguidos de cinco casos de mastite, um caso de endometrite, um caso de pneumonia e um caso de morbidade febril. Se agruparmos essas infecções em pertencentes a complicações maiores ou menores, utilizada em boa parte dos trabalhos internacionais que avaliam infecção em pacientes infectadas pelo HIV, ocorreu 1 caso infeccioso de complicação maior $(2,9 \%)$ e 33 casos de complicações menores $(97,1 \%)$. Das 207 pacientes estudadas, a incidência de complicações maiores foi de $0,48 \%$ e a de complicações menores foi de $15,9 \%$.

Observou-se que a duração do ato cirúrgico, o tempo decorrido entre a rotura das membranas e o parto, a duração do trabalho de parto, uso ou não de antibioticoterapia profilática, assim como a contagem de células $\mathrm{CD}^{+}$no final da gestação não interferiram na taxa de morbidade febril puerperal, quando avaliados de forma isolada.

No estudo com grávidas infectadas pelo HIV devemos sempre pensar em dois aspectos: a TMF do vírus HIV e as complicações clínicas e obstétricas que podem ocorrer com mais freqüência neste grupo de pacientes. Quanto à transmissão do HIV, a cesárea continua sendo vantajosa para redução da TMF, principalmente nas gestantes que não freqüentaram pré-natal adequadamente ou que foram mal orientadas quanto ao uso de drogas anti-retrovirais. Por outro lado, mesmo em pacientes imunocompetentes, a cesárea acarreta maiores taxas de complicações clinicas, principalmente morbidade febril puerperal, tanto naquelas realizadas de forma eletiva como nas não-eletivas. Outro fato ainda que deve ser lembrado é o risco de prematuridade iatrogênica quando se opta pela resolução programada por cesárea.

O pré-natal, quando realizado adequadamente, e o parto, bem conduzido nos casos de parto vaginal ou na cesárea eletiva, podem ser fatores importantes na redução das complicações maternas e neonatais, com menores taxas de TMF do HIV e infecção materna. 


\section{ABSTRACT}

Purpose: the morbidity in HIV-positive patients due to puerperal fever was studied and correlated to the method and duration of labor, the duration of premature rupture of the membranes, $C D 4^{+}$cell count and the viral load (VL) at peridelivery.

Methods: a total of 207 HIV-positive women with prenatal examinations and deliveries between May 1997 and December 2001 were enrolled. Of these, 32 had natural childbirth and 175 had a cesarean section. Of the total of enrolled patients, $62.8 \%$ were submitted to elective cesarean section. The average age of the group was 27.4 years, and $25.6 \%$ were nulliparous and $26 \%$ were primiparous. At the moment of the delivery the average gestational age was 37.8 weeks. At the end of pregnancy the average of the $\mathrm{CD}^{+}$cell count was approximately 481 cells $/ \mathrm{mm}^{3}$ and the viral load 49,100 copies $/ \mathrm{mL}$.

Results: puerperal morbidity occurred in 34 patients, with 33 after cesarean section and one after natural childbirth. The most usual intercurrent post-cesarean infection was that of the surgical wound (13\% of the infection cases). Analyzed factors, such as delivery duration, duration of rupture of the membranes, number of $\mathrm{CD}^{+}$cells or the viral load at peridelivery, did not interfere in puerperal morbidity.

Conclusions: puerperal morbidity was $16.8 \%$ and occurred more frequently after cesarean sections (18.9\%) than after vaginal deliveries $(3.1 \%)$. The other factors did not present a significant effect on puerperal morbidity.

KEYWORDS: AIDS. Puerperal morbidity. Vertical transmission. Cesarean section. Vaginal delivery.

\section{Referências}

1. Connor EM, Sperling RS, Gelber R, et al. Reduction of maternal-infant transmission of human immunodeficiency virus type 1 with zidovudine treatment. Pediatric AIDS Clinical Trials Group Protocol 076 Study Group. N Engl J Med 1994; 331:1173-80.
2. Frenkel LM. Cesarean section and/or HAART. What's an HIV-1 infected pregnant woman to do? Proceedings of the $6^{\text {th }}$ Conference on Retroviruses and Opportunistic Infections; 1999 Jan 31-Feb 4; Chicago, USA, 1999.

3. Rehu M, Nilsson C. Risk factors for febrile morbidity associated with cesarean section. Obstet Gynecol 1980; 56:269-73.

4. van Ham MA, van Dongen PW, Mulder J. Maternal consequences of caesarean section. A retrospective study of intra-operative and postoperative maternal complications of caesarean section during a 10-year period. Eur J Obstet Gynecol Reprod Biol 1997; 74:1-6.

5. Semprini AE, Castagna C, Ravizza M, et al. The incidence of complications after caesarean section in 156 HIV-positive women. AIDS 1995; 9:913-7.

6. Watts DH, Lambert JS, Stiehm ER, et al. Complications according to mode of delivery among human immunodeficiency virus infected women with $\mathrm{CD}^{+}$lymphocyte counts of $<$or $=500 /$ microL. Am J Obstet Gynecol 2000; 183:100-7.

7. Grubert TA, Reindell D, Kastner R, Lutz-Friedrich $\mathrm{R}$, Belohradsky $\mathrm{BH}$, Dathe O. Complications after caesarean section in HIV-1 infected women not taking antiretroviral treatment. Lancet 1999; 354:1612-3.

8. Vimercati A, Greco P, Loverro G, Lopalco PL, Pansini V, Selvaggi L. Maternal complications after cesarean section in HIV infected women. Eur J Obstet Gynecol Reprod Biol 2000; 90:73-6.

9. Rodriguez EJ, Spann C, Jamieson D, Lindsay M. Postoperative morbidity associated with cesarean delivery among human immunodeficiency virusseropositive women. Am J Obstet Gynecol 2001; 184:1108-11.

10. Nosocomial infection rates for interhospital comparison: limitations and possible solutions. A report from the National Nosocomial Infections Surveillance System (NNISS). Infect Control Hosp Epidemiol 1991:12:609-21.

11.Hanna G, Hueppchen N, Kriebs J, Moore R, Anderson J, Pressman E. Post-cesarean febrile morbidity in HIV-infected patients. Am J Obstet Gynecol 1997; 176:S59. 